\title{
La indumentaria masculina en clave social. Córdoba, gobernación del Tucumán, 1574-1620
}

Resumen: El presente artículo aborda el problema de la indumentaria masculina, particularmente entre los sectores medios y altos de la sociedad cordobesa temprano-colonial para explorar la manera en que las materialidades pudieron configurar, y no solo expresar, las diferencias sociales en una de las ciudades más meridionales del virreinato del Perú. A partir de un corpus documental compuesto fundamentalmente por inventarios post mortem, pero también por procesos judiciales, relaciones y actas capitulares, se busca reconocer no solo los rasgos estéticos de la indumentaria masculina, sino reflexionar sobre su contexto histórico particular y la dinámica general que subyace a la elección o adopción de un estilo vestimentario específico.

Palabras clave: sociedad colonial, desigualdad social, vestimenta.

\section{Men's clothing from a social perspective. Córdoba, government of Tucumán, 1574-1620}

Abstract: This article addresses the issue of men's clothing, particularly among the middle and upper sectors of earlycolonial Cordovan society to explore the way in which materialities could configure, and not only express, social differences in one of the most southern cities in the Viceroyalty of Peru. Starting from a documentary corpus composed mainly of post-mortem inventories, but also of judicial processes, relaciones and actas capitulares, it seeks to recognize not only the aesthetic features of men's clothing, but also to reflect on the particular historical context and the general dynamics that underlie the choice or adoption of a specific clothing style.

Keywords: colonial society, social inequality, clothing.

\section{A indumentária masculina em chave social. Córdoba, governo de Tucuman, 1574-1620}

Resumo: Este artigo aborda o problema da indumentária masculina, particularmente entre os setores médio e alto da sociedade colonial de Córdoba, para explorar a maneira pela qual as materialidades puderam configurar, e não apenas expressar, as diferenças sociais em uma das cidades mais ao sul do Vice-reinado do Peru. A partir de um corpus documental composto fundamentalmente de inventários post-mortem, mas também de processos judiciais, relações e atas capitulares, o objetivo é reconhecer não apenas as características estéticas da indumentária masculina, mas também refletir sobre seu contexto histórico particular e a dinâmica geral que subjaz à escolha ou adoção de um estilo de roupa específico.

Palavras-chave: sociedade colonial, desigualdade social, vestuário.

Cómo citar este artículo: Constanza González Navarro, "La indumentaria masculina en clave social. Córdoba, gobernación del Tucumán, 1574-1620”, Trashumante. Revista Americana de Historia Socia/17 [2021]: 56-79.

DOI: 10.17533/udea.trahs.n17a03

Fecha de recepción: 6 de abril de 2020
Fecha de aprobación: 23 de julio de 2020

Constanza González Navarro: Doctora en Historia por la Universidad Nacional de Córdoba. Investigadora adjunta del Consejo Nacional de Investigaciones Científicas y Técnicas [Conicet]. Profesora Asistente de la Universidad Nacional de Córdoba. ORCID: 0000-0002-3309-271X.

Correo electrónico: constanzagn70@yahoo.com.ar 


\title{
La indumentaria masculina en clave social. Córdoba, gobernación del Tucumán, 1574-1620
}

\author{
Constanza González Navarro
}

\section{Introducción}

$E_{\mathrm{s}}^{\mathrm{n}}$ 1957 Roland Barthes se refería críticamente a la historia de la indumentaria. renovación en el abordaje del tema y nadie se había ocupado de definir un "sistema vestimentario", esto es, "el conjunto axiológico (restricciones, prohibiciones, tolerancias, aberraciones, fantasías, congruencias y exclusiones) que lo constituye". Proponía, entonces, una sociología del vestido que mostraba el delicado juego entre las opciones individuales y la estructura normativa de cada sociedad. Esta mirada procesual, estructural y social que fue común a las primeras generaciones de Annales, entendemos que marcó un antes y un después en la historia de la indumentaria. En 1967 Barthes publicaba Système de la mode en el que proporcionaba un enfoque semiótico de esta. ${ }^{2}$ En 1979 Fernand Braudel lanzaba Civilisation matérielle, économie et capitalisme, $X V^{t}$-XVIII siècle y destinaba uno de sus capítulos a la historia de los trajes y la moda en el mundo europeo. ${ }^{3}$

Pero no solo los intelectuales franceses realizaron aportes en esta línea de trabajo, Norbert Elias publicó El proceso de la civilización en 1939. Si bien Elias no se dedicó específicamente a la historia de la indumentaria, toda su teoría sociológica sirve para comprender el papel que juegan las materialidades en el proceso macrosocial y microsocial. Tal como expresa el autor, el proceso de civilización que sufren las sociedades modernas se caracteriza tanto por la disminución de los temores externos como por el aumento de los miedos internos automáticos con el respectivo fortalecimiento de los mecanismos de autocoacción. Esta dinámica que experimentó la sociedad europea desde el siglo XV hasta el XIX se tradujo en cambios concretos respecto de las concepciones sobre la desnudez y el vestido,

1. Roland Barthes, "Histoire et sociologie du vêtement. Quelques observations méthodologiques", Annales. Économies, Sociétés, Civilisations 12.3 (1957): 430-441.

2. Roland Barthes, El sistema de la moda y otros escritos (Barcelona: Paidós, 2003).

3. Fernand Braudel, Civilización material, economía y capitalismo. Siglos XV-XVIII, 3 tomos (Madrid: Alianza Editorial, 1984). 
la regulación y modelación de la vida impulsiva y la aparición de "utensilios" de la civilización como el tenedor, el pañuelo de nariz y la ropa de cama. ${ }^{4} \mathrm{Si}$ nos referimos a aportes más recientes y específicos sobre la historia de la indumentaria durante el Antiguo Régimen, podemos señalar a autores de la talla de Daniel Roche y Raffaella Sarti cuya principal contribución ha sido demostrar el poder modelador y "performativo" de las materialidades. ${ }^{5}$

La historiografia del mundo hispánico fue recibiendo de forma más tardía las contribuciones antes señaladas, centró la atención en el estudio de la literatura del Siglo de Oro español y procuró proporcionar un panorama general del vestido en el territorio de la monarquía hispánica, sus telas y los cambios en la moda. ${ }^{6}$

Otras producciones más recientes con aportes significativos para la historia de la indumentaria de la época de los Austrias en el mundo iberoamericano son los textos de Israel Lasmarías Ponz, Francisco de Sousa Congosto, Patrícia Victòria Martínez i Àlvarez, Carmen Rodríguez de Tembleque, Arianna Giorgi, José María Imízcoz Beunza, Máximo García Fernández y Javier Esteban Ochoa de Eribe, entre otros. ${ }^{7}$ En tanto, un conjunto importante de estudios se refieren a la lexicografia del mundo de los textiles, verbigracia Marta Pérez Toral, entre otros. ${ }^{8}$

La historiografia colonial cordobesa, por su parte, no ha dedicado especial atención a este tópico, excepto en lo que se refiere a los siglos XVIII y XIX abordados por Ana María Martínez de Sánchez y, más recientemente, por Cecilia Moreyra, quienes proporcionaron investigaciones en este sentido desde un enfoque de la historia de la vida cotidiana vista a través de las materialidades. ${ }^{9}$ La historia de la

4. Norbert Elias, El proceso de la civilización. Investigaciones sociogenéticas y psicogenéticas (México: Fondo de Cultura Económica, 2012) 253.

5. Daniel Roche, La culture des apparences. Une histoire du vêtement. XVIIe-XVIIIe siècle (París: Fayard, 1989); Raffaella Sarti, Vida en familia. Casa, comida y vestido en la Europa moderna (Barcelona: Crítica, 2003).

6. Miguel Herrero García, Estudios sobre indumentaria española en la época de los Austrias (Madrid: Centro de Estudios de Europa Hispánica, 2014); Miguel Herrero García, Los tejidos en la España de los Austrias. Fragmentos de un diccionario (Madrid: Centro de Estudios de Europa Hispánica, 2014).

7. Véase Israel Lasmarías Ponz, "El traje popular en el siglo XVII", Ars Longa 18 (2009): 133142; Francisco de Sousa Congosto, Introducción a la historia de la indumentaria en España (Madrid: Ediciones Istmo, 2007); Carmen Rodríguez de Tembleque, "Un traje para la insinuación, la provocación y el recato" (Ponencia, Congreso Internacional Imagen Apariencia, Universidad de Murcia, 2008). https://digitum.um.es/digitum/bitstream/10201/44430/1/ CongresoImagen144.pdf (03/09/2020); Arianna Giorgi, "El vestido y la elocuencia del botón. Galas y significado en el estético discurso de la aparente distinción cultural masculina" (Ponencia, Congreso Internacional Imagen Apariencia, Universidad de Murcia, 2008). https://digitum. um.es/digitum/bitstream/10201/43463/1/CongresoImagen96.pdf (03/09/2020); José María Imízcoz Beunza y otros, coords., Procesos de civilización: culturas de élites, culturas populares. Una historia de contrastes y tensiones (siglos XVI-XIX) (Bilbao: Universidad del País Vasco, 2019).

8. Marta Pérez Toral, "Tejidos y textiles en la vida cotidiana del siglo XVII", Revista de Investigación Lingüística 20 (2017): 195-219; Marta Pérez Toral, "El léxico de tejidos en inventarios notariales del siglo XVII", Revista de Lexicografía 23 (2017): 157-184. DOI: 10.17979/rlex.2017.23.0.4701.

9. Entre los trabajos de estas autoras están Ana María Martínez de Sánchez, "Indumentaria, 'ser' y 
indumentaria en la sociedad temprano colonial es, entonces, un territorio bastante virgen para el caso de Córdoba — no así para otros espacios coloniales_ ${ }^{10}$ probablemente por las dificultades que encierra su abordaje y el poco interés que despertó, hasta ahora, en los historiadores colonialistas.

Nuestro objetivo se centrará en delinear algunos de los rasgos diferenciales de la indumentaria de los sectores medios y altos de la sociedad cordobesa, con lo que se reconocerá parcialmente el contexto que incidió en las elecciones de vestimenta y se mostrará el modo en que tales elecciones contribuyeron a configurar la pertenencia a un colectivo social. En la misma línea que Roche, Sarti y Fanny Oudin podemos decir que la indumentaria reposa sobre el principio de "visibilidad" y posee una dimensión pragmática que no solo consiste en proteger al hombre contra la intemperie, además tiene una dimensión dinámica y activa que "no se contenta con significar el ser de quien la porta, sino que contribuye a crearlo". ${ }^{11}$ Sin duda, este es apenas el puntapié inicial de un abordaje que procuraremos ir profundizando con el desarrollo de la investigación en el tiempo.

Sobre la metodología de trabajo y el corpus se debe afirmar que la información sobre la temática se encuentra no solo dispersa en muy variados tipos de documentos, sino que los datos consignados privilegian a los sectores acomodados de la sociedad con mayor cantidad de bienes heredables. A su vez, los testimonios materiales son muy limitados para el caso de Córdoba donde las colecciones de los museos presentan muy pocos vestigios de la vida cotidiana y menos aún de textiles o representaciones pictóricas no religiosas. Sin duda, estas carencias condicionan nuestra metodología de abordaje, pero no la obstaculizan totalmente. Los tipos de registros que utilizamos en esta ocasión provienen de los inventarios de bienes post mortem, algunos procesos judiciales específicos, todos ellos correspondientes al fondo de Tribunales de Justicia del Archivo Histórico de la Provincia de Córdoba (AHPC).

'parecer' en la Córdoba del setecientos", Páginas sobre Hispanoamérica colonial. Sociedad y cultura, vol. 1 (Buenos Aires: Publicación del Programa de Investigaciones sobre Hispanoamérica Colonial / Consejo Nacional de Investigaciones Científicas y Técnicas, 1994) 13-39; Ana María Martínez de Sánchez, Formas de la vida cotidiana en Córdoba (1573-1810). Espacio, tiempo y sociedad (Córdoba: Centro de Investigaciones y Estudios sobre Cultura y Sociedad, 2011); Cecilia Moreyra, "Entre lo íntimo y lo público: la vestimenta en la ciudad de Córdoba a fines del siglo XVIII", Fronteras de la Historia 15.2 (2010):388-413; Cecilia Moreyra, "La ropa, lo masculino y lo civilizado. La vestimenta de los hombres en Córdoba (Argentina), siglo XIX”, Temas Americanistas 33 (2014): 88-112.

10. Véase Ana María Presta, "Undressing the Coya and Dressing the Indian Woman: Market Economy, Clothing, and Identities in the Colonial Andes, La Plata (Charcas), Late Sixteenth and Early Seventeenth Centuries", Hispanic American Historical Review 90.1 (2010): 41-74.DOI:10.1215/001821682009-090.

11. Fanny Oudin, "L'habit fait-il le moine? Quelques réflexions autour des proverbes vestimentaires du Moyen Âge”, Questes. Revue Pluridisciplinaire d’Études Médiévales 25 (2013): 121-124. DOI: 10.4000/questes.137. 
El corpus está compuesto por un conjunto de 26 inventarios de bienes post mortem, ${ }^{12}$ de los cuales seis corresponden a miembros de sectores medios (un tendero, dos pobleros, un médico y un maestro) y los otros 20 a miembros de la élite (en su mayoría vecinos encomenderos, primeros pobladores o descendientes de ellos, grandes comerciantes y solo un eclesiástico, vicario de la ciudad), ubicados cronológicamente entre 1574 y 1621. Los integrantes de esta muestra tienen en común el origen hispano o portugués, con la única excepción del indígena chileno Gonzalo, yanacona y poblero, que, si bien poseía un origen étnico diferente, pudo integrarse a los estratos medios rurales de la sociedad cordobesa. No todos los inventarios tienen el mismo nivel de integridad como fuente. ${ }^{13}$ No obstante las limitaciones, decidimos incluirlos porque consideramos que, aunque sus guardarropas cuentan con carencias, pueden al menos darnos una indicación de tendencias en las preferencias de uso. En efecto, para la fecha indicada se registra un total de 53 inventarios de bienes de hombres en el AHPC, de los cuales analizamos en este trabajo un 50\% en función de las posibilidades de acceso. Complementariamente utilizamos otras fuentes provenientes de los procesos judiciales coloniales, actas capitulares y relaciones. La metodología complementa el análisis cuantitativo de las prendas por guardarropa, volcadas y sistematizadas en una planilla de cálculo, que aporta indicadores de las preferencias indumentarias con un análisis cualitativo que identifica y describe de forma general los tipos de combinaciones posibles, materias primas y colores.

\section{La indumentaria masculina: "hábito de indio" y "hábito de español”}

La sociedad colonial era desigual en esencia, en virtud de un orden natural aceptado y reproducido con cada acto de la vida diaria. Cada persona tenía una inscripción

12. Los inventarios pertenecen a Blas de Rosales (1574), Antón Berrú (1582), Alonso Martines (1582), Indio Gonzalo (1584), Juan Martin (1584), Juan Bautista Noble (1586), Bernabe Mexia (1589), Andres Paxon (1592), Blas de Peralta (1592), Gerónimo de Bustamante (1593), Juan de Soria (1593), Martin de Salvatierra (1595), Diego de Funes (1596), Diego Xuares Bauiano (1598), Francisco Martines (1598), Pedro de Candia (1600), Melchor Ramires Camacho (1601), Gabriel Perez Beltran (1603), Joan de Belmonte (1604), Phelipe de San Anton (1605), Joan Diaz de Ocaña (1608), Rafael Antonio Palencia (1608), Manuel de Fonseca (circa 1612), Pedro Olmedo (1613), Francisco Narbaez (1614), Miguel Gonzalez Jaime (1621). AHPC, Córdoba, Escribanía. 1, leg. 1, exp. 1 y 8; AHPC, Córdoba, Escribanía 1, leg. 2, exp. 5 y 10;AHPC, Córdoba, Escribanía 1, leg. 3, exp. 7 y 8; AHPC, Córdoba, Escribanía 1, leg. 5, exp. 2, 5, 7, 9 y 14;AHPC, Córdoba, Escribanía 1, leg. 7, exp. 4, 7 y 8; AHPC, Córdoba, Escribanía 1, leg. 10, exp. 1 y 9; AHPC, Córdoba, Escribanía 1, leg. 11, exp. 2;AHPC, Córdoba, Escribanía 1, leg. 17, exp. 12;AHPC, Córdoba, Escribanía 1, leg. 18, exp. 3 y 4;AHPC, Córdoba, Escribanía 1, leg. 22, exp. 2;AHPC, Córdoba, Escribanía 1, leg. 23, exp. 1;AHPC, Córdoba, Escribanía 1, leg. 29, exp. 3;AHPC, Córdoba, Escribanía 1, leg. 30, exp. 11;AHPC, Córdoba, Escribanía 1, leg. 31, exp. 1;AHPC, Córdoba, Escribanía 1, leg. 35, exp. 2 y 3;AHPC, Córdoba, Escribanía 1, leg. 52, exp. 2.

13. María Marchoff, "Reflexiones arqueológicas en torno a la metodología de análisis de los inventarios post mortem del fondo de justicia colonial de Córdoba", Prácticas de producción, ordenamiento y conservación del Fondo de Justicia colonial de Córdoba, dir. Constanza González Navarro (Córdoba: Centro de Estudios Históricos “Prof. Carlos S.A. Segreti”, 2017) 88-108. 
social que condicionaba todos sus movimientos y estaba signada por el origen, la etnia y el género.

La ciudad de Córdoba se constituyó como una de las fundaciones más tardías y meridionales de América española y su sociedad tuvo en principio ciertos rasgos de flexibilidad que permitieron la movilidad social al menos en la primera generación de pobladores. ${ }^{14}$ A grandes rasgos podemos decir que a fines del siglo XVI la sociedad estaba conformada por la élite de vecinos beneméritos que habían acompañado la fundación de la ciudad o su proceso de poblamiento. Con el tiempo, este grupo fue engrosado por los descendientes de los conquistadores iniciales que heredaron los títulos y las preeminencias sociales. Este segmento de la sociedad fue el que asumió la categoría de vecino-encomendero. Un escalón por debajo se encontraban los vecinos a secas que eran aquellos pobladores que tenían casa propia, eran casados y estaban asentados en la ciudad. Ambos segmentos estaban facultados para ocupar puestos del cabildo y atender a la defensa de la ciudad. En la base de la pirámide se encontraba la población indígena y los esclavos de origen africano. Dentro de la población indígena también había diferencias: una mayoría sometida al sistema de encomiendas, mientras otro tanto no había logrado reducirse. También los indios forasteros, provenientes mayormente de Chile o Perú, formaban parte de la población indígena local, adscrita generalmente bajo la categoría de yanaconas - por encontrarse desvinculados de sus comunidades de origen- podían formar alianzas con los vecinos y ocupar puestos de confianza como mayordomos o pobleros. De estos sujetos puede decirse que no pertenecían a los sectores subalternos sino a la amplia y heterogénea masa que integraba a los sectores medios con diversas y variables categorías de residencia (residentes, moradores, estantes). En efecto, los sectores medios no conformaban un grupo en el sentido sociológico del término, pero se caracterizaban por ser sujetos jurídicamente libres, poseer un oficio o saber útil y no haber sido integrados a la élite fundadora.Allí encontramos artesanos, profesionales liberales, pequeños comerciantes, mayordomos, etcétera. ${ }^{15}$

Dicho esto, afirmamos que la indumentaria era una de las formas a través de las cuales se marcaban las diferencias sociales y también podía configurar un marcador cultural de "civilidad", en función de las concepciones vigentes en la época cuando la desnudez era signo de pobreza y barbarie. ${ }^{16}$ El propio lenguaje daba cuenta de la importancia de la vestimenta en la configuración social al señalar que un sujeto estaba en "hábito de indio" o en "hábito de español”.

14. Beatriz Bixio, "Mestizos, testamentos y configuraciones sociales en Córdoba colonial”, Mestizaje y configuración social, Córdoba (siglos XVI y XVII), dirs. Beatriz Bixio y Constanza González Navarro (Córdoba: Editorial Brujas, 2013) 19-84.

15. Para una mejor caracterización de este segmento véase Beatriz Bixio y Constanza González Navarro, "Reflexiones acerca de los segmentos medios en la sociedad colonial temprana de Córdoba del Tucumán (1573-1620)", Revista Complutense de Historia de América 45 (2019): 135-158. DOI: $10.5209 /$ rcha. 64690 .

16. Pilar Gonzalbo Aizpuru, Introducción a la historia de la vida cotidiana (México: El Colegio de México, 2006) 224. 
Ahora bien, ¿qué significaba estar en hábito de indio? Muy poco se ha escrito sobre ello debido a la escasez de información con que contamos. Según el Diccionario de autoridades "hábito" se define como "el vestido o trage que cada uno trahe segun su estado, ministério o Nación". ${ }^{17}$ Claramente, el "hábito" hacía referencia al vestido y cómo este moldeaba una determinada apariencia y pertenencia de un sujeto.

Los documentos más tempranos de las primeras entradas a la región describen a los nativos vestidos con mantas y camisetas con las cuales se cubrían sus "vergüenzas". Es el caso del cronista Gerónimo de Bibar y de la Relación Anónima. Ambas fuentes coinciden en la existencia de "camisetas" tejidas de lana, las que describían, además, con muchas labores en las aberturas, ruedos y bocamangas. ${ }^{18}$ También se mencionan tocados y adornos en la cabeza.

Algunos registros documentales posteriores indican que la vestimenta indígena masculina habría conservado estas características hacia principios del siglo XVII. Siguió teniendo presencia el uso de la manta ${ }^{19}$ y la camiseta, ${ }^{20}$ a la vez que se mencionan el calzón, el sombrero y la túnica. Esta última, más propia de los incas, según refiere Jean-Jaques Decoster, parece haberse extendido también a esta región meridional. ${ }^{21} \mathrm{Al}$ menos así lo refleja el inventario de la tienda de Francisco de Narváez (1614) en el cual se listaron "seis sombreros de indios para forrar [...] cinco camisetas de indios $[. .$.$] cincuenta tunicas de indios". { }^{22}$ Es de suponer que esta ropa no habría sido adquirida directamente por los nativos, sino por sus amos, ya que como parte de las obligaciones los encomenderos debían - aunque no siempre lo hicieran - evangelizarlos, vestirlos y cuidarlos en sus enfermedades. ${ }^{23} \mathrm{El}$ cumplimiento de este deber sirvió para homogeneizar en cierta medida la apariencia de los indios colonizados, aunque no descartamos que hayan existido ciertas diferencias estéticas mientras los nativos pudieron continuar con su producción textil doméstica propia.

En otros casos la provisión de la vestimenta a la población indígena, en particular la urbana, estaba en manos de los sectores artesanales de la ciudad que proporcionaban

17. Diccionario de Autoridades, t. 4 (Madrid: Real Academia Española, 1734). http://web.frl.es/ DA.html (03/09/2020).

18. Beatriz Bixio y Eduardo E. Berberián, Crónicas y relaciones sobre el antiguo Tucumán, siglo XVI (Córdoba: Centro de Estudios Históricos "Prof. Carlos S.A. Segreti” / Encuentro Grupo Editor, 2017) 289.

19. "Procesos criminales contra Andres indio". AHPC, Córdoba, Escribanía 1, leg. 6, exp. 3, f. 179v.

20. El Diccionario de Autoridades define "Camiseta. s. f. dim. de Camísa. La camísa corta, y con mangas anchas". Diccionario de Autoridades, t. 2 (Madrid: Real Academia Española, 1729). http://web.frl. es/DA.html (03/09/2020).

21. Jean-Jacques Decoster, “La identidad étnica y la manipulación cultural. La indumentaria inca en la época colonial", Estudios Atacameños 29 (2005): 163-170.

22. "Año de 1615. Inbentario y almoneda de los bienes fincados por muerte de Francisco Narvaez". AHPC, Córdoba, Escribanía 1, leg. 35, exp. 2.

23. Josefina Piana de Cuestas, Los indígenas de Córdoba bajo el régimen colonial (1570-1620) (Córdoba: Dirección General de Publicaciones de la Universidad Nacional de Córdoba, 1992). 
la ropa a sus aprendices. ${ }^{24}$ Mientras la mayoría de los contratistas entregaba a los indios manta, camiseta y calzón de telas ordinarias, algunos artesanos que concertaban indios chilenos o peruanos entregaban indumentaria de mejores calidades textiles e incluían otras prendas como camisa y capa. ${ }^{25}$

Respecto a los esclavos de origen africano es poco lo que sabemos en este periodo temprano debido, en parte, a que el flujo de la trata solo utilizaba la ciudad de Córdoba como plaza de venta y distribución para seguir hacia otras regiones. ${ }^{26}$ Solo una pequeña parte podía integrarse en la sociedad cordobesa. Josefina Piana ha señalado que los textiles procedentes de los obrajes indígenas eran utilizados también para la vestimenta de los esclavos. ${ }^{27}$

Finalmente, los mestizos biológicos que ocupaban un lugar ambiguo en la sociedad siempre fueron adscritos a uno de los dos extremos de la escala según llevaran "hábito de indio" o "hábito de español". Beatriz Bixio expresa con claridad la distinción forzada que fijaba la normativa de la época: "le valen las leyes para los indios si anda en hábito de indio; es español y le valen las leyes para los españoles si lleva vestido de español". ${ }^{28}$ Este carácter diacrítico de la vestimenta como una forma de superar las zonas grises por parte de la legislación contribuyó también a poner en marcha ciertas estrategias de mimetización. En efecto, algunos mestizos utilizaban el "hábito de español" para contribuir a su proceso de asimilación al grupo hispánico. El vestido permitía el reconocimiento de las distancias sociales; no había vestido de mestizo, se era español o indio sin términos medios.

Ahora bien, vestir "traje de español” o "hábito de español” ¿qué implicaba? Según lo que se desprende del presente análisis, corresponde a la indumentaria que habrían usado preferentemente los sectores medios y altos de la sociedad colonial americana y que analizaremos a continuación.

\section{Tipos de prendas de los sectores medios y altos. Prendas interiores, semiinteriores y exteriores}

Las prendas masculinas de fines del siglo XVI y principios del siglo XVII compartían muchas similitudes con las prendas utilizadas por los contemporáneos peninsulares. El vestuario se componía de un conjunto de piezas que se superponían unas a otras en diferentes capas con telas de diversas texturas que provocaban visualmente "un

24. Constanza González Navarro, "El ejercicio de las artes manuales en talleres y obrajes de Córdoba (1573-1650): prácticas, relaciones e intercambios culturales”, Mestizaje y configuración social, Córdoba (siglos XVI y XVII), dirs. Beatriz Bixio y Constanza González Navarro (Córdoba: Editorial Brujas, 2013) 131-158.

25. González Navarro 143.

26. Carlos Sempat Assadourian, El tráfico de esclavos en Córdoba, 1588-1610, según las actas de protocolos del Archivo Histórico de Córdoba (Córdoba: Dirección General de Publicaciones de la Universidad Nacional de Córdoba, 1965).

27. Piana de Cuestas 188.

28. Bixio 30-31. 
torso que parecía ir alojado en el peto de una armadura". ${ }^{29}$ Las prendas del vestuario masculino se encontraban divididas en numerosas porciones (mucho más que hoy en día) que se ensamblaban unas a otras con tirillas, correas, ligas y botones que aseguraban la correcta sujeción al cuerpo.

Uno de los aspectos generales que podemos afirmar luego del análisis de los 26 guardarropas masculinos relevados es que ninguna prenda se repite de manera absoluta en todos ellos. Existe una gran variabilidad en las piezas de la indumentaria: 21 categorías de prendas, cuatro tipos de calzado y ocho tipos de accesorios, además de la indumentaria militar (seis prendas corporales y 10 tipos de armas). Esta variedad, sin embargo, se correlaciona con el hecho de que muchas podían cumplir funciones similares de protección, por ejemplo: calzas, calzones, valones, gregüescos y zaragüelles; botas y borceguíes; capa, capote y herreruelo, entre otros.

La diferencia entre prendas interiores, semiinteriores y exteriores es la primera distinción que debemos hacer. En el mundo peninsular los hombres de los sectores medios y altos usaban ropa interior que se componía básicamente de camisa y calzoncillos; la primera cubría el torso y brazos, llegaba inclusive a tapar parte de las piernas, y la segunda cubría el abdomen y las piernas. ${ }^{30}$ Sobre estas prendas más livianas — generalmente de lienzo blanco- que estaban en contacto directo con la piel se colocaban otras más pesadas y engalanadas. En Córdoba las camisas como prendas interiores estaban representadas en al menos 11 de los 26 guardarropas (Tabla 1), de materiales tales como el lienzo de algodón, lienzo de lino, ruan y, excepcionalmente, una tela rústica americana denominada chaguar. También aparece la camiseta como una variante de esta en tres guardarropas de los analizados, elaborados con "lana de algodón". Los calzoncillos mencionados por Herrero García para el caso peninsular, sin embargo, no fueron registrados en ninguno de los inventarios cordobeses, aunque sí se han detectado en los inventarios del siglo siguiente. ${ }^{31}$ Si bien, como señala el autor, con frecuencia los bienes que se listaban en los inventarios utilizaban otros vocablos alternativos para referirse a los calzoncillos, como por ejemplo los "valones" - término utilizado en la época de los Austrias - no encontramos dicha correspondencia para Córdoba, en cuanto el vocablo "valones" no remite a una prenda interior liviana, sino más bien a una exterior mucho más pesada, confeccionada con terciopelos, tafetanes, entre otros materiales, y engalanada para ser exhibida y no ocultada a las miradas ajenas. La omisión de los calzoncillos, por tanto, podemos atribuirla a su escaso valor

29. De Sousa Congosto 125.

30. Herrero García, Estudios sobre indumentaria 20-25.

31. Una muestra al azar realizada sobre un conjunto de 15 inventarios de hombres ubicados entre 1751 y 1761 muestra la presencia de calzoncillos de lienzo, crea o bretaña en ocho de ellos, mientras los demás casos solo registran camisas como ropa interior. AHPC, Córdoba, Escribanía 1, leg. 311, exp. 1, 16 y 22;AHPC, Córdoba, Escribanía 1, leg. 323, exp. 3, 4 y 8; AHPC, Córdoba, Escribanía 1, leg. 324, exp. 6; AHPC, Córdoba, Escribanía 1, leg. 325, exp. 2; AHPC, Córdoba, Escribanía 1, leg. 343, exp. 1; AHPC, Córdoba, Escribanía 1, leg. 344, exp. 3; AHPC, Córdoba, Escribanía 2, leg. 30, exp. 20 y 23; AHPC, Córdoba, Escribanía 3, leg. 2, exp. 3 y 5. 
Tabla 1. Cantidad y frecuencia de prendas interiores, semiinteriores y exteriores

\begin{tabular}{|c|c|c|}
\hline Prenda & $\begin{array}{c}\text { Cantidad total de } \\
\text { prendas }\end{array}$ & $\begin{array}{l}\text { Número de guarda- } \\
\text { rropas que incluyen la } \\
\text { prenda }\end{array}$ \\
\hline Herreruelo & 16 & 10 \\
\hline Capa & 29 & 19 \\
\hline Capote & 1 & 1 \\
\hline Capotillo & 1 & 1 \\
\hline Mangas & 10 & 8 \\
\hline Cuello & 14 & 4 \\
\hline Balandrán & 3 & 3 \\
\hline Sayo & 27 & 14 \\
\hline Ropilla & 25 & 10 \\
\hline Jubón & 23 & 13 \\
\hline Coleto & 3 & 3 \\
\hline Camisa & 38 & 10 \\
\hline Camiseta & 5 & 3 \\
\hline Medias & 3 & 2 \\
\hline Zaragüelles & 7 & 2 \\
\hline Ligas & 2 & 1 \\
\hline Calzones & 14 & 8 \\
\hline Calzas & 13 & 8 \\
\hline Cañones & 2 & 1 \\
\hline Valones & 20 & 11 \\
\hline Gregüescos & 6 & 5 \\
\hline
\end{tabular}

de inventario, pero también a su poco e infrecuente uso. En el mismo sentido se orientan las investigaciones de Raffaella Sarti y Francisco de Sousa Congosto que afirman que tanto para Europa moderna en general como el mundo hispánico en particular la camisa constituía la prenda interior por excelencia. ${ }^{32}$

La camisa en Córdoba no estaba generalizada en todos los guardarropas. Si consideramos los inventarios en los que se registran camisas y camisetas (13 en 
total) el número de prendas de este tipo que podía tener un sujeto oscilaba entre un mínimo de una a un máximo de seis. En ciertos casos su número no habría permitido un recambio continuo.

Las camisas, por otro lado, iban unidas a cuellos y puños desmontables que alcanzaban a ser visibles y cuya blancura podía dar cuenta de la mayor o menor pulcritud del sujeto. En efecto, el juego de las apariencias que era común a las sociedades del Antiguo Régimen estaba, ciertamente, presente en América a pesar de los condicionamientos que tenía para acceder al vestuario y telas europeas. Si bien mudarse de camisa con frecuencia no era factible para todos, lo importante era, por cierto, siempre revelar la blancura de puños y cuellos.

Por encima de la camisa existía una combinación de piezas semiinteriores y exteriores que podían alternar de diferente manera. Dentro de las "prendas semiinteriores" podemos mencionar el jubón, denominación que remite a una pieza que se usaba sobre el torso arriba de la camisa, equivalente, aunque no idéntico, al chaleco actual sin mangas, o inclusive con mangas desmontables. El jubón podía ir unido directamente a otras prendas exteriores como las "calzas atacadas" mediante lazos, o bien separada totalmente como ocurría con el calzón que también cubría el abdomen y parte superior de las piernas. Si bien estos dos diferentes usos son asociados por Herrero García a dos épocas y modas diferentes, ${ }^{33}$ una anterior a 1621 y otra posterior a esa fecha, en Córdoba nos encontramos con la presencia simultánea de calzas, calzones, valones, gregüescos y zaragüelles, todas prendas que cumplían la función de cubrir el cuerpo desde la cintura hasta las rodillas. Puede verse, inclusive, en un mismo guardarropa la convivencia de estilos y usos impuestos en el mundo peninsular en diferentes momentos. Esto se condice con la dinámica de reutilización permanente de la indumentaria o "reciclaje del vestido usado" que menciona Máximo García Fernández en el seno de la unidad familiar hispánica. ${ }^{34}$ La venta en almoneda también constituía un medio importante de circulación de prendas que quedaban en desuso y se adquirían a menor precio que las nuevas. Ello contribuía a engrosar un poco los austeros guardarropas.

Así pues, encontramos que los guardarropas de los miembros de la élite benemérita incluyen tanto calzas y gregüescos como valones y calzones. Es el caso de Blas de Peralta, cuyo inventario fue realizado entre 1592 y 1593 e incluía unos gregüescos de terciopelo morado con pasamanos de oro y dos pares de calzas de terciopelo, ${ }^{35}$ el inventario de Rafael Antonio Palencia (1608) contaba con unas calzas de raja negra aforradas con raso carmesí y unos calzones de raso aforrados en tafetán azul. ${ }^{36}$ También los valones eran prendas que podían encontrarse en los

33. Herrero García, Estudios sobre indumentaria 89.

34. Máximo García Fernández, "Contrastes sociales y apariencia personal: el ajuar civilizador", Procesos de civilización: culturas de élites, culturas populares. Una historia de contrastes y tensiones (siglos XVI-XIX), coords. José María Imízcoz Beunza y otros (Bilbao: Universidad del País Vasco, 2019) 33.

35. "Blas de Peralta, sucesión universal de sus bienes”. AHPC, Córdoba, Escribanía 1, leg. 10, exp. 1.

36. "Luis de Argüello como albacea de doña Barbara de Maldonado contra Jhoan Nieto y el capitán Pantaleon Marques Correa ”. AHPC, Córdoba, Escribanía 1, leg. 23, exp. 1. 
inventarios de la élite, como es el caso de Luis de Abreu y Albornoz que poseía cuatro pares de valones de diferentes telas o el de Diego Xuares Babiano (vicario de la ciudad) que contaba con dos pares de ellos confeccionados en terciopelo negro y paño pardo.

Estas prendas también se encuentran en los guardarropas de los sectores medios, confeccionadas con telas más sencillas y baratas como el paño, sayal, lana o rajeta. La única prenda que cubría el torso inferior y piernas que no se encuentra registrada en los inventarios de la élite son los zaragüelles, un tipo de calzón bastante holgado confeccionado de lana, algodón o lienzo que aparece citado solo en el caso de los guardarropas de Gonzalo, indio yanacona, y Francisco de Narváez, tendero.

Las prendas exteriores se disponían encima de las prendas interiores (camisa, camiseta, calzoncillos, si hubiere) y semiinteriores (jubón). Como mencionamos más arriba, los calzones, valones, calzas, gregüescos y zaragüelles cubrían la mitad inferior del torso y piernas hasta las rodillas y, generalmente, se combinaban con medias, ligas y zapatos, botas o, en su defecto, zapatos y borceguíes superpuestos.

En la mitad superior del cuerpo el jubón era cubierto por la ropilla, una especie de chaqueta de aspecto militar, entallada en el torso y suelta a partir de la cintura. Generalmente abotonada en el medio, podía tener o no mangas. ${ }^{37}$ Juan de Soria, por ejemplo, poseía una ropilla de paño pardo sin mangas y otra "de terciopelo labrado guarnecido y sus mangas de raso". ${ }^{38}$ Las texturas podían variar de un caso a otro. Así, hallamos ropillas pesadas y livianas, lujosas o más sencillas, confeccionadas de terciopelo, paño de Segovia, raja, jergueta, gorborán, gorborán de México, raso, mezcla, forradas algunas de ellas en tafetán.

Otra prenda que podía ir encima del jubón, en vez de la ropilla, era el sayo; un tipo de casaca abotonada que cubría todo el torso, brazos y resto del cuerpo hasta las rodillas. A diferencia de la península, en el caso cordobés, el sayo se encuentra presente tanto entre los sectores altos como medios y, si bien no aparece adornada de forma lujosa, no podemos identificarla con un uso estrictamente rural o urbano. En colores pardo, negro y azul, aparece confeccionado de textiles como el paño de Londres, paño de Castilla, terciopelo y mezcla. A diferencia de la ropilla que se registra en 10 de los 26 inventarios, el sayo lo hace en 14 de ellos, asimismo, se encontró cierta preferencia en el uso de esta prenda por parte de Juan Martín, cirujano, que poseía cinco sayos y ninguna ropilla.

Finalmente, entre las prendas exteriores quedan comprendidas también las de abrigo como la capa, el herreruelo o ferreruelo, el capote, el capotillo y el coleto. Los cuatro primeros eran propios del uso urbano, mientras que el coleto, casi siempre de ante o cordobán, era utilizado en viajes o trajines.

Respecto al calzado, hemos de decir que, aunque no todos los listados lo mencionan, seguramente debido a su desgaste y escaso valor de inventario había cierta

37. Herrero García, Estudios sobre indumentaria 107-108.

38. "El licenciado Antonio Rosillo solicita rendición de cuentas de los bienes de los menores hijos de Juan de Soria difunto”. AHPC, Córdoba, Escribanía 1, leg. 11, exp. 2. 
preferencia por los borceguíes que eran un tipo de calzado ajustado, elaborado de badana o gamuza que cubría el pie y la pierna hasta la rodilla y que podía usarse solo o dentro de los zapatos y pantuflos. Las alpargatas eran calzados más sencillos y rústicos con menor representación, aunque no totalmente ausente de los guardarropas de los vecinos y residentes de origen peninsular. En este punto cabe señalar que el uso del calzado de estilo europeo no era común a todos los sectores sociales (Tabla 2).

Tabla 2. El calzado

\begin{tabular}{|c|c|c|}
\hline Prenda & $\begin{array}{l}\text { Cantidad total de cada } \\
\text { prenda }\end{array}$ & $\begin{array}{l}\text { Número de guarda-rropas } \\
\text { que incluyen la prenda }\end{array}$ \\
\hline Alpargatas & 4 & 2 \\
\hline Pantuflos & 2 & 2 \\
\hline Zapatos & 4 & 3 \\
\hline Borceguíes & 14 & 6 \\
\hline
\end{tabular}

Sobre las costumbres indígenas poco sabemos, y es de presumir que estuvieran descalzos o utilizaran alpargatas, ya que estas últimas eran elaboradas por ellos mismos y entregadas en concepto de tributo en el Tucumán (según ordenanza número 87 de Francisco de Alfaro). ${ }^{39}$ Su uso está tímidamente registrado en algunas fuentes. ${ }^{40}$ El calzado, en efecto, marcaba una verdadera divisoria social entre los sectores más bajos y los medios y altos.

\section{El vestido}

Según muestran los inventarios analizados, la palabra "vestido" remite a todas las combinaciones posibles entre las diferentes prendas exteriores y semiinteriores, algunas de las cuales eran confeccionadas con telas similares o engalanadas con adornos que combinaban. La decisión y, a la vez, la posibilidad de "combinar" los mismos tejidos, galones, texturas o colores en dos o más prendas era un signo de distinción no compartido por todos los habitantes de la ciudad. La toma de decisión en el vestir, por lo tanto, no solo era condicionada por el poder adquisitivo de cada sujeto, la disponibilidad de los materiales y la oferta de hábiles artesanos, sino

39. Francisco de Alfaro, "Carta del Licenciado D. Francisco de Alfaro, oidor de la Real Audiencia de la Plata a S.M. San Miguel del Tucumán, 23 de enero de 1612". Correspondencia de la Ciudad de Buenos Ayres con los reyes de España, vol. II, ed. Roberto Leviller (Buenos Aires: Municipalidad de Buenos Aires, 1918).

40. Un viajero compra en el camino dos pares de alpargatas para el indio que lo acompañaba. "Sucesión de Juan de Avila y Zárate”. AHPC, Córdoba, Escribanía 1, leg. 49, exp. 1. 
también por el deseo de configurar una determinada apariencia. Sin duda, cada conjunto iba mucho más allá de la función necesaria de abrigo de toda vestimenta.

Así, por ejemplo, el vecino Francisco Martínez registra en su inventario de bienes de 1598 varios vestidos, uno de los cuales estaba compuesto por "un herreruelo de mescla raxa de berde y asul y un sayo de lo propio y balones de terciopelo berde labrado con su pasamano de alquimia viejo". En otro ejemplo, Juan de Soria, en 1593, combinaba en un mismo vestido tres piezas nuevas de paño pardo de Chile: una ropilla forrada "en gatillos", calzones con pasamanos de seda parda y un herreruelo. Este conjunto iba acompañado de un jubón de telilla viejo.

Las combinaciones posibles del "vestido" de hombre halladas en los inventarios remiten en la mayoría de los casos al traje civil, mientras que solo en uno, al traje clerical.Veamos las posibilidades de combinación de prendas:

1. Capa, sayo y gregüescos.

2. Herreruelo o ferreruelo, sayo y valones.

3. Capa, ropilla y valones.

4. Herreruelo, jubón, mangas y valones.

5. Ferreruelo, ropilla y calzón.

6. Herreruelo, ropilla y valones.

7. Capa, ropilla y calzones.

8. Manteo, sotana y bonete (clerical).

En general, los colores de las prendas exteriores y semiinteriores podían ser: negro, pardo, azul y, en menor medida, verde, leonado y "flor de romero" (lila). Como sabemos, el negro era un color característico de la nobleza española e independientemente del tipo de prenda, formaba parte de todos los guardarropas de los sectores altos de la sociedad cordobesa. ${ }^{41}$

Los colores vivos son casi inexistentes, solo Gonzalo, indio, posee unos zaragüelles de lana colorados. En el caso de los calzones, calzas, valones y gregüescos podían albergar dos combinaciones de textiles y colores en su interior y exterior. Su diseño holgado y de apariencia redondeada de colores sobrios incluía algunas veces la presencia de rajas que contrastaban y dejaban entrever otras telas de colores intensos. Es el caso del guardarropa de Gerónimo de Bustamante que incluía "unas calzas negras acuchilladas con aforro de tela colorada". ${ }^{42}$

La indumentaria también poseía detalles en hilos de oro o alquimia, botones de diferentes materiales y cintas de seda de colores que engalanaban las prendas exteriores. Francisco Martines contaba con unos "balones de terciopelo berde labrado con su pasamano de alquimia”, ${ }^{43}$ mientras que el escribano Joan Díaz de

41. Sarti 261.

42. "Geronima de Albornoz solicita el reintegro de su carta dotal por la muerte de su primer marido Gerónimo de Bustamante, vecino encomendero”. AHPC, Córdoba, Escribanía 1, leg. 18, exp. 4.

43. “Apertura de testamento de Francisco Martines vecino".AHPC, Córdoba, Escribanía 1, leg. 7, exp. 8. 
Ocaña tenía unos valones "de terciopelo leonado con pasamanos y abrochados con botones de hilo de oro". ${ }^{44}$ Si bien los inventarios son bastante mezquinos en la descripción de las prendas, es posible afirmar que había una provisión importante de estos elementos de adorno, pasamanería e hilos de distintos tipos en las tiendas locales. Los inventarios realizados a la muerte de Juan de Soria, tratante (1588), ${ }^{45}$ y Francisco de Narváez, tendero (1614), muestran que contaban con un stock importante de estos insumos para la confección de prendas masculinas y femeninas, provenientes de diferentes geografias.

Narváez tenía en su tienda una importante provisión de telas y otros insumos europeos y orientales que incluían: madejas de alambre grueso, sartas de cuentas azules, piezas de cinta blanca de algodón, rollos de cintas de hilo y de seda, telas como holanda, lienzo de algodón, paño, anascote, cordellate, telilla montilla y frailesca, ruan de fardo, bombasí, cambray, tafetán de la China, caniquí, seda floja retorcida de colores de la China, lienzo brin, bretangil, rajeta, etcétera. ${ }^{46}$

La confección de la indumentaria podía realizarse tanto de forma doméstica como encargada a los artesanos locales (sastres, zapateros, sederos, sombrereros, etcétera). ${ }^{47}$ El trabajo artesanal doméstico está atestiguado tempranamente en la visita de $1598,{ }^{48}$ realizada sobre la base de 16 viviendas españolas que registraron 28 indígenas sujetos al sistema de encomienda con saberes vinculados a la elaboración de indumentaria; de los cuales entre los hombres había seis sastres, cinco cordobaneros, cinco zapateros y un curtidor, y entre las mujeres se encontraban tres costureras, cuatro labranderas y cuatro bolilleras. ${ }^{49} \mathrm{Si}$ bien los nativos tenían conocimientos propios de la elaboración de tejidos y trabajo con cuero, las fuentes indican que la tecnología utilizada era mayormente la europea en función de las demandadas de la sociedad colonial. A la par de estos artesanos estaban los de origen europeo, que luego de transitar por diversos lugares y espacios del continente americano terminaban arribando a Córdoba en busca de oportunidades. Algunos de estos sujetos, al menos 22 , han podido ser identificados a través de las escrituras públicas, aunque seguramente otros habrán transitado por esta ciudad sin dejar ningún registro escrito. ${ }^{50}$ Esta confección artesanal de los oficiales independientes

44. "Quentas que se tomaron a Antonia de Queuedo tutora y curadora de la persona y bienes de Juan Diaz de Ocaña menor hijo de Juan Diaz de Ocaña”. AHPC, Córdoba, Escribanía 1, leg. 22, exp. 3.

45. "El licenciado Antonio Rosillo solicita rendición de cuentas de los bienes de los menores hijos de Juan de Soria difunto". AHPC, Córdoba, Escribanía 1, leg. 11, exp. 2.

46. "Año de 1615. Inbentario y almoneda de los bienes fincados por muerte de Francisco Narvaez". AHPC, Córdoba, Escribanía 1, leg. 35, exp. 2.

47. González Navarro 131-164.

48. "Visita a los indios de servicio de la ciudad de Córdoba del Tucumán en 1598", Historiografía y Bibliografía Americanistas 31.1 (1987): 27-61.

49. Arte del bolillo: "Palo pequeño y torneado que sirve para hacer encajes y pasamanería". Diccionario de la Lengua Española, 23a edición, 2019. https://dle.rae.es/bolillo (03/09/2020).

50. Número obtenido del relevamiento en fuentes varias: protocolos, actas capitulares, recibos de pago en juicios sucesorios, etcétera. 
ha quedado también registrada en los numerosos, aunque dispersos, recibos de pago por servicios que quedan albergados en procesos judiciales. ${ }^{51}$

Podemos decir, entonces, que la producción local de indumentaria estaba garantizada por la presencia de hábiles artesanos que trabajaban en el espacio doméstico para sus propios amos, ${ }^{52}$ o bien por los numerosos talleres urbanos que existían. Esta afirmación se ve corroborada, además, por los registros de "cortes" de tela para prendas de vestir (en 10 de 26 inventarios), piezas de cordobán (cuatro de 26) y herramientas de costura como tijeras, agujas, alfileres, dedales, instrumentos de medición, entre otras (seis de 26) que mencionan los inventarios relevados.

\section{Entre lo necesario y lo superfluo}

En este apartado analizamos todos aquellos objetos, en apariencia accesorios, que formaban parte de la indumentaria. Junto con el vestido - entendido como conjunto de prendas combinadas-, estos objetos no solo cumplían una función específica (abrigo, defensa, adorno, entre otras), sino que eran importantes en la configuración de la imagen personal y estima social de los sectores medios y altos de Córdoba. Eran, en efecto, exclusivos de estos segmentos y servían ante todo para marcar diferencias y producir distinciones. Algunos de ellos pueden considerarse objetos de lujo en el sentido amplio, ya que podían proporcionar el placer de los sentidos a sus portadores, podían considerarse un exceso en el marco de la norma, y eran claramente ostentatorios (como podía ocurrir con una prenda engalanada de hilos de oro y plata).$^{53}$ Pero no todos estos objetos entraban bajo esta categoría. En todo caso su rasgo común era su carácter exclusivo y ostentatorio en la medida que solo algunos miembros de la sociedad podían usarlos, so pena de perder su valor. En palabras de Peter Burke, se trata de objetos que al ser usados y exhibidos configuraban una imagen favorable de su portador; no necesariamente se vinculaban con la magnificencia, sino que podían asociarse a la simplicidad como la golilla utilizada por Felipe IV e imitada por toda su corte..$^{54}$

Por ejemplo, la botonería puede considerarse como el "emblema de las vanidades masculinas". ${ }^{55}$ Según expresa Arianna Giorgi, no surgió para sujetar la ropa,

51. Véase el recibo del sastre Jorge Lozada por hechura de una saya. "Miguel de Vidauri y Maria Pereira, rendición de cuentas de la tutela y curatela de los menores hijos de Martin de Salvatierra". AHPC, Córdoba, Escribanía 1, leg. 17, exp. 12, f. 237r.

52. No hemos detectado para este periodo temprano la presencia de esclavos de origen africano que realizaran confección o guarnición de indumentaria en las casas de morada. Este fenómeno empieza a ser detectado con el avance del siglo XVII cuando la población esclava asentada en la ciudad empieza a ser más numerosa por efecto de la caída demográfica de la población indígena. Por ejemplo, Francisco Gil Negrete contaba con un esclavo "bordador" hacia 1656."Sucesión de Francisco Gil Negrete”. AHPC, Córdoba, Escribanía 1, leg. 107, exp. 1.

53. Yves Michaud, El nuevo lujo. Experiencias, arrogancia, autenticidad (Buenos Aires:Taurus, 2015) 46-47.

54. Peter Burke, "Res et verba: Conspicuous Consumption in the Early Modern World", Consumption and the World of Goods, eds. John Brewer y Roy Porter (Londres: Routledge, 2005) 148-161.

55. Giorgi, "El vestido y la elocuencia" 11. 
sino para adornarla. En las prendas que hemos analizado no se descarta su funcionalidad para sujeción, pero se destaca sobre todo su valor como adorno y elegancia: botones de hilo de oro y plata, botones chapadillos, de seda, de cristal, de alquimia, etcétera. La pasamanería y las guarniciones adquieren el mismo sentido en este contexto. Los materiales mencionados en las tiendas y en los inventarios post mortem permiten reconocer que, a pesar de la austeridad de la naciente ciudad de Córdoba, sus pobladores de los sectores altos y medios podían recurrir a variedad de géneros o guarniciones, algunas de ellas prohibidas por las leyes suntuarias.

Otros "accesorios" circulantes en el mundo masculino eran los sombreros, gorras y bonetes; en los dos primeros casos remiten a la indumentaria civil, mientras que el bonete corresponde a la vestimenta religiosa. Eran detalles de elegancia, pero también de reparo contra el clima. Se encontraban elaborados generalmente de paño, aunque no se hallan muchas descripciones sobre ellos.

Por su parte, talabartes, tiros y pretinas correspondían a los accesorios que servían para portar la espada. Este tipo de objeto claramente se correlaciona con el hecho de que todos los sujetos que tenían la condición de vecino, en especial los vecinos-encomenderos, estaban obligados a asistir a la defensa de la ciudad. ${ }^{56}$ Los demás pobladores europeos también las portaban, aunque no estuvieran alcanzados por dicha obligación. Las armas solo estaban vedadas a la población indígena y esclava, así como a otros grupos subalternos. ${ }^{57}$ En efecto, en los 26 inventarios que hemos analizado, 23 de ellos registran armas y/o armaduras. Entre las armas encontramos espadas de diferente tipo y calidad, pero también dagas, cuchillos, arcabuces, lanzas, bordones, pistoletes, partesanas y mosquetes. En 13 casos estos sujetos también contaban con elementos de protección corporal como cotas, corazas, celadas, adargas, rodelas y escaupiles. Junto al caballo, como se sabe, estos elementos eran claros signos de poder y distinción social que también se extendieron a algunos miembros de los segmentos medios. El análisis particular de estos elementos requeriría un tratamiento específico que no es posible desarrollar aquí, no obstante, es importante señalar la gran circulación que habrían tenido este tipo de objetos en el mundo colonial, al punto que un escaupil mexica pudo ser reutilizado en la América meridional.

Otro objeto que merece nuestra atención es el pañuelo. Este elemento fue considerado por Norbert Elias como esencial para el mundo civilizado de los siglos XVIII y XIX. Al decir del autor, el pañuelo de nariz era una tecnología de la civilización, en tanto indicaba la aparición de un umbral de vergüenza que marcaba los límites de lo permitido a nivel del comportamiento social. Se relacionaba con los buenos modales y costumbres, los hábitos cortesanos en esencia. Lo llamativo es que estos artefactos ya están tímidamente presentes en nuestros inventarios de fines del siglo XVI y principios del XVII. De todos los sujetos relevados solo cinco

56. Héctor Ramón Lobos, Historia de Córdoba. Raíces y fundamentos, t. 1 (Córdoba: Ediciones El Copista, 2009) 527.

57. Juan Sempere y Guarinos, Historia del luxo, y de las leyes suntuarias de España (Madrid: Imprenta Real, 1788) 104. 
tenían pañuelos de narices. Uno era Juan Martín, cirujano, quien poseía tres pañuelos que fueron rematados a su muerte en almoneda pública junto con sus vestidos y prendas, lo cual da cuenta de su estimación social. Nadie habría comprado en un remate un pañuelo solo para limpiarse la nariz, sino porque evidentemente se trataba de un objeto llamativo y poco corriente entre los pobladores de una ciudad pequeña. Esta exigua presencia podría estar indicando que las concepciones de higiene, cortesía y civilización que Elias destaca para el mundo europeo, especialmente para la Francia de los siglos XVII y XVIII, aún estaban poco definidas en la América meridional. Las casas de morada de los vecinos eran lugares de cobijo más que de socialización ${ }^{58}$ y la poca cantidad de prendas que poseía cada individuo - comparada con sus pares europeos o con los guardarropas del siglo siguiente - sugiere escasas posibilidades de recambio y una higiene personal muy limitada al "baño en seco". ${ }^{59}$ Esto se confirma con el hecho de que no existían baños públicos, ni mobiliario específico (tinas) destinado al aseo personal en las casas de morada y en el total de casos relevados solo hallamos cuatro sujetos que poseían paños de $\operatorname{manos}^{60}$ (toallas de mano) y tres contados casos con panes de jabón en su haber.

El cuidado personal de los sectores medios y altos no se vincula entonces a la higiene integral del cuerpo, sino a la búsqueda del cuidado de las apariencias con detalles distinguidos como botones, cintas, pasamanos, telas lujosas e incluso joyas. ${ }^{61}$ Las armas servían para defensa, pero también como un atavío que contribuía a dibujar una figura notoria, varonil, erguida y con rasgos militares, algo que irá diluyéndose en el siglo XVIII con la influencia de las modas francesas marcadas por la delicadeza, el refinamiento y otros detalles cortesanos. ${ }^{62}$

La preocupación por las apariencias habría ido de la mano con un sistema de valor o valor social - como expresa Barthes - en el cual las jerarquías sociales, la identidad de género, el decoro y el prestigio estaban antes que la comodidad,

58. Constanza González Navarro y María Marschoff,"Materialidades y prácticas en el interior de las casas de morada de la ciudad de Córdoba, Argentina (siglos XVI y XVII)", Población \& Sociedad 26.1 (2019): 60-89. DOI: $10.19137 /$ pys-2019-260104.

59. Sarti 251.

60. "Paño de Manos, de Mesa, \&c.: La toalla o lienzo con que se limpian quando se llavan, o con que se cubre la mesa. Latín. Manutergium. ANT. AGUST. Dial. de Med. pl. 131. Hace señal con un paño de manos, que en Latín dicen Mappa. L. GRAC. Critic. part. 3. Cris. 5. Descogian los paños de mesa, mas no desplegaban los labios". Diccionario de Autoridades, t. 5 (Madrid: Real Academia Española, 1737). http://web.frl.es/DA.html (03/09/2020).

61. No hemos dedicado especial atención a las joyas porque estas, además de ser un adorno, representaban un objeto de ahorro fácilmente intercambiable por otros bienes, con lo cual no es posible saber hasta qué punto sus poseedores las lucían en público. De los casos analizados solo cinco poseen joyas entre las que se mencionan zarcillos, anillos, rosarios, agnus dei de oro, cintillos.

62. Arianna Giorgi, "Petimetre y majo, afrancesado y castizo: nuevas identidades indumentarias en el Madrid borbónico", Procesos de civilización: culturas de élites, culturas populares. Una historia de contrastes y tensiones (siglos XVI-XIX), coords. José María Imízcoz Beunza y otros (Bilbao: Universidad del País Vasco, 2019) 51-72. 
practicidad y accesibilidad. No hay, sin embargo, entre los sujetos analizados un afán desmedido por acumular gran número de prendas de lujo.

Aun los sujetos más pudientes, como es el caso de Joan Díaz de Ocaña (escribano, encomendero y tratante) o Luis de Abreu y Albornoz (encomendero y floreciente comerciante) no cuentan con más de cuatro vestidos (conjuntos) de ropa, mientras que la mayoría cuenta con uno o dos vestidos y algunas prendas sueltas. Esta situación puede haberse visto influida por el predicamento católico que menospreciaba la vanidad en el vestido; ${ }^{63}$ pero no necesariamente, ya que dicho discurso no había hecho mella en otros territorios de la monarquía hispánica. Tampoco podemos explicar este fenómeno por la imposibilidad económica de comprar mayor número de prendas, ya que los vecinos principales contaban con medios suficientes para adquirirlas. Así, por ejemplo, Joan Díaz de Ocaña a su muerte poseía un capital acumulado de 18,572 pesos de los cuales solo 737 pesos estaban constituidos por su guardarropa, armas y accesorios para montar, es decir, apenas un $4 \%$ de su capital total. De manera tal que, aunque este sujeto estaba en posibilidad económica de adquirir un guardarropas más variado, no lo había hecho. Desafortunadamente no contamos con tasaciones de todos los sujetos cuyos procesos sucesorios hemos relevado para poder realizar estimaciones comparativas. El caso de Díaz de Ocaña, sin embargo, nos permite reconocer que la restricción en el gasto de ropa no estaba vinculada a la pobreza económica, al menos no en el mundo preindustrial analizado. En la misma línea, Daniel Roche observó para el caso francés que a fines del siglo XVII existían diferentes sensibilidades vestimentarias en tanto "la ropa más lujosa y abundante no se encontraba automáticamente allí donde estaban las grandes fortunas". ${ }^{64}$

Las restricciones en el gasto o en el consumo excesivo tampoco estaban vinculadas a la imposibilidad de acceder a los productos por la vía comercial o a la aplicación estricta de las leyes suntuarias por parte del cabildo. En el primer caso, los análisis de Carlos Sempat Assadourian han revelado que entre 1580 y 1610 el comercio interregional fue activo y que existía un movimiento constante de ganado vacuno y ovino en pie y textiles bastos provenientes de los obrajes hacia los centros urbanos del alto Perú, principalmente al eje Lima-Potosí. ${ }^{65}$ Ese flujo habría permitido a los vecinos de Córdoba acceder a bienes de lujo disponibles en el mercado procedente del circuito de la Carrera de Indias o del Galeón de Manila. También el comercio a través del puerto de Buenos Aires habría permitido entre 1590 y 1610 un flujo importante de harina de trigo, sayales, sebos y cecinas (fruto del trabajo indígena), que retornaban con esclavos y bienes de

63. Los textos de Fray Luis de Granada eran particularmente insistentes en este punto y hay registro de que estaban presentes en las bibliotecas de algunos vecinos.

64. Roche 108-109.

65. Carlos Sempat Assadourian, El sistema de la economía colonial. Mercado interno, regiones y espacio económico (México: Editorial Nueva Imagen, 1983) 33. 
Castilla procedentes de los navíos de registro, o del comercio con Brasil por vía legal o por contrabando. ${ }^{66}$

Estos datos permiten reconocer, a pesar del monopolio, el dinamismo del movimiento comercial de media y larga distancia, al menos hasta que la caída demográfica de la población indígena se hizo sentir (entre 1610 y 1620). No obstante esta coyuntura favorable, el retorno de los movimientos comerciales no se reflejó en un acopio excesivo de prendas de carácter suntuario por parte de los vecinos principales, aspecto que habla del sistema de valores que subyacía a la elección vestimentaria.

Por otro lado, tampoco se encuentran referencias del cabildo de la ciudad al incumplimiento de las leyes suntuarias. ${ }^{67} \mathrm{Si}$ bien estas normativas existían desde los tiempos de los Reyes Católicos, ${ }^{68}$ en Córdoba, por lo menos hasta 1620 , se advierte una ausencia de sanciones o referencias a ellas. ${ }^{69}$ El exceso y el lujo vestimentario no eran fenómenos que representaran una preocupación para las autoridades de la ciudad y, en todo caso, mostraba mayor inquietud por la provisión de bienes y la fijación de precios de las telas ${ }^{70}$ y las hechuras de las prendas ${ }^{71}$ que con frecuencia violaban la normativa, ya fuera por su mala calidad o por su excesivo precio. Esta dinámica seguramente se relaciona con el hecho de que Córdoba aún no había experimentado los cambios de la revolución del consumo del siglo siguiente. ${ }^{72}$ Por otro lado, si las leyes suntuarias servían para prohibir a las capas inferiores el apropiarse de los símbolos de prestigio de las capas superiores, en Córdoba no había aún nuevos grupos enriquecidos que aspiraran a los objetos vestimentarios propios de los sectores más altos y que, por lo tanto, pudieran promover un borramiento de las fronteras sociales. Los mestizos representaban una parte pequeña de la población integrada, según el caso, al grupo indígena o al español, pero no constituían un grupo con identidad propia que pudiera constituir, merced

66. Piana de Cuestas, Los indígenas de Córdoba 180-187.

67. Carlos Luque Colombres, ed., Actas capitulares, t. 1 (Córdoba: Archivo Municipal de Córdoba, 1974); Luis Santillán Vélez, ed., Archivo Municipal de Córdoba, libros 2 y 3 (Córdoba: Establecimiento Tipográfico del Eco de Córdoba, 1882); Luis Santillán Vélez, ed., Archivo Municipal de Córdoba, libro 4 (Córdoba: Establecimiento Tipográfico del Eco de Córdoba, 1883); Luis Santillán Vélez, ed., Archivo Municipal de Córdoba, libros 5 y 6 (Córdoba: Establecimiento Tipográfico del Eco de Córdoba, 1884).

68. García Fernández, "Contrastes sociales y apariencia personal” 39.

69. Con la única excepción de las prohibiciones referidas al uso de sillas de manos que tanto daño habían hecho a los nativos. González Navarro y Marschoff,"Materialidades y prácticas" 73.

70. Acta del 19 de agosto de 1617. "Los sayales que en esta ciudad se venden de presente son lacios y sin torcer y muy angostos y se venden a excesivos precios como si fueran sayales buenos y torcidos y se recibe daño a la ciudad". Santillán Vélez, Archivo Municipal de Córdoba, t. 5.

71. "Acta del 4 de diciembre de 1612"; "Acta del 17 de diciembre de 1612". Santillán Vélez, Archivo Municipal de Córdoba, t. 5.

72. Jan de Vries, The Industrious Revolution. Consumer Behavior and Household Economy, 1650 to the Present (New York: Cambridge University Press, 2008). 
a su capacidad de mimetización y poder adquisitivo, una amenaza para las estructuras sociales vigentes. De esto se desprende la poca vigencia de las leyes suntuarias.

\section{Consideraciones finales}

La indumentaria masculina de los sectores medios y altos de fines del siglo XVI y principios del XVII se asemejaba en gran medida a la peninsular, aunque a nivel local habrían convivido estilos originados en diferentes momentos. En el periodo siguiente, estimamos, se irá definiendo un estilo propio.

La indumentaria imprimía y fortalecía las fronteras sociales con gran claridad, los sectores medios y altos consumían un mismo tipo de prendas, aunque las telas y las guarniciones variaran en función de las posibilidades económicas. Aquellos que accedían a materiales lujosos tenían la posibilidad de destacarse aún más y este afán de distinción no se habría expresado en el acopio de un guardarropas demasiado abundante y provisto, pero sí en la opción por uno o dos vestidos (conjuntos) que pudieran contar con los detalles necesarios (botones, adornos, accesorios) o la exhibición de un arma o una montura engalanada para configurar la imagen personal ostensible ante la mirada ajena. Mirada que provenía de los grupos subalternos de los cuales había que diferenciarse y distanciarse, pero también de todos aquellos sujetos que compartían el mismo rango social al cual se aspiraba a pertenecer o seguir perteneciendo.

Sin duda este fenómeno del uso y el consumo vestimentario requeriría un más profundo análisis comparativo con los comportamientos de la población femenina, así como un análisis del flujo comercial legal e ilegal de la época para tener un panorama completo, cuestión que aquí apenas hemos mencionado por exceder los objetivos del trabajo.

\section{Fuentes}

\section{Manuscritas}

Archivo Histórico de la Provincia de Córdoba, Córdoba (AHPC) Escribanía 1, 2 y 3

\section{Impresas}

Bixio, Beatriz y Eduardo E. Berberián. Eds. Crónicas y relaciones sobre el antiguo Tucumán, Siglo XVI. Córdoba: Centro de Estudios Históricos "Prof. Carlos S.A. Segreti" / Encuentro Grupo Editor, 2017.

De Alfaro, Francisco. "Carta del Licenciado D. Francisco de Alfaro, oidor de la Real Audiencia de la Plata a S.M. San Miguel del Tucumán, 23 de Enero de 1612". Correspondencia de la Ciudad de Buenos Ayres con los reyes de España.Volumen II. Ed. Roberto Leviller. Buenos Aires: Municipalidad de Buenos Aires, 1918. 
Luque Colombres, Carlos. Ed. Actas capitulares. Tomo 1. Córdoba: Archivo Municipal de Córdoba, 1974.

Sempere y Guarinos, Juan. Historia del luxo, y de las leyes suntuarias de España. Madrid: Imprenta Real, 1788.

Santillán Vélez, Luis. Ed. Archivo Municipal de Córdoba. Libros 2 y 3. Córdoba: Establecimiento Tipográfico del Eco de Córdoba, 1882.

. Archivo Municipal de Córdoba. Libro 4. Córdoba: Establecimiento Tipográfico del Eco de Córdoba, 1883.

- Archivo Municipal de Córdoba. Libros 5 y 6. Córdoba: Establecimiento Tipográfico del Eco de Córdoba, 1884.

"Visita a los indios de servicio de la ciudad de Córdoba del Tucumán en 1598". Historiografía y Bibliografía Americanistas 31.1 (1987): 27-61.

\section{Bibliografía}

Assadourian, Carlos Sempat. El sistema de la economía colonial. Mercado interno, regiones y espacio económico. México: Editorial Nueva Imagen, 1983.

. El tráfico de esclavos en Córdoba, 1588-1610, según las actas de protocolos del Archivo Histórico de Córdoba. Córdoba: Dirección General de Publicaciones de la Universidad Nacional de Córdoba, 1965.

Barthes, Roland. El sistema de la moda y otros escritos. Barcelona: Paidós, 2003. . "Histoire et sociologie du vêtement. Quelques observations méthodologiques”. Annales. Économies, Sociétés, Civilisations 12.3 (1957): 430-441.

Bixio, Beatriz. "Mestizos, testamentos y configuraciones sociales en Córdoba colonial". Mestizaje y configuración social. Córdoba (siglos XVI y XVII). Dirs. Beatriz Bixio y Constanza González Navarro. Córdoba: Editorial Brujas, 2013.

Bixio, Beatriz y Constanza González Navarro. "Reflexiones acerca de los segmentos medios en la sociedad colonial temprana de Córdoba del Tucumán (1573-1620)". Revista Complutense de Historia de América 45 (2019): 135158. DOI: $10.5209 /$ rcha.64690.

Braudel, Fernand. Civilización material, economía y capitalismo. Siglos XV-XVIII. 3 Tomos. Madrid: Alianza Editorial, 1984.

Burke, Peter. "Res et verba: Conspicuous Consumption in the Early Modern World". Consumption and the World of Goods. Eds. John Brewer y Roy Porter. Londres: Routledge, 2005.

De Sousa Congosto, Francisco. Introducción a la historia de la indumentaria en España. Madrid: Ediciones Istmo, 2007.

DeVries, Jan. The Industrious Revolution. Consumer Behavior and Household Economy, 1650 to the Present. New York: Cambridge University Press, 2008.

Decoster, Jean-Jacques. "La identidad étnica y la manipulación cultural. La indumentaria inca en la época colonial”. Estudios Atacameños 29 (2005): 163-170. 
Elias, Norbert. El proceso de la civilización. Investigaciones sociogenéticas y psicogenéticas. México: Fondo de Cultura Económica, 2012.

García Fernández, Máximo. "Contrastes sociales y apariencia personal: el ajuar civilizador”. Procesos de civilización: culturas de élites, culturas populares. Una historia de contrastes y tensiones (siglos XVI-XIX). Coords. José Imízcoz Beunza y otros. Bilbao: Universidad del País Vasco, 2019.

Giorgi, Arianna. "El vestido y la elocuencia del botón. Galas y significado en el estético discurso de la aparente distinción cultural masculina". Ponencia, Congreso Internacional Imagen Apariencia, Universidad de Murcia, 2008. https://dialnet.unirioja.es/servlet/libro? codigo $=357306$ (03/09/2020).

. "Petimetre y majo, afrancesado y castizo:nuevas identidades indumentarias en el Madrid borbónico". Procesos de civilización: culturas de élites, culturas populares. Una historia de contrastes y tensiones (siglos XVI-XIX). Coords. José María Imízcoz Beunza y otros. Bilbao: Universidad del País Vasco, 2019.

Gonzalbo Aizpuru, Pilar. Introducción a la historia de la vida cotidiana. México: El Colegio de México, 2006.

González Navarro, Constanza. "El ejercicio de las artes manuales en talleres y obrajes de Córdoba (1573-1650): prácticas, relaciones e intercambios culturales". Mestizaje y configuración social, Córdoba (siglos XVI y XVII). Dirs. Beatriz Bixio y Constanza González Navarro. Córdoba: Editorial Brujas, 2013.

González Navarro, Constanza y María Marschoff."Materialidades y prácticas en el interior de las casas de morada de la ciudad de Córdoba, Argentina (siglos XVI y XVII)". Población \& Sociedad 26.1 (2019): 60-89. DOI: 10.19137/ pys-2019-260104.

Herrero García, Miguel. Estudios sobre indumentaria española en la época de los Austrias. Madrid: Centro de Estudios de Europa Hispánica, 2014.

. Los tejidos en la España de los Austrias. Fragmentos de un diccionario. Madrid: Centro de Estudios de Europa Hispánica, 2014.

Imízcoz Beunza, José María y otros. Coords. Procesos de civilización: culturas de élites, culturas populares. Una historia de contrastes y tensiones (siglos XVI-XIX). Bilbao: Universidad del País Vasco, 2019.

Lasmarías Ponz, Israel. "El traje popular en el siglo XVII”. Ars Longa 18 (2009): 133-142.

Lobos, Héctor Ramón. Historia de Córdoba. Raíces y fundamentos. Tomo 1. Córdoba: Ediciones El Copista, 2009.

Marchoff, María. "Reflexiones arqueológicas en torno a la metodología de análisis de los inventarios post mortem del fondo de justicia colonial de Córdoba". Prácticas de producción, ordenamiento y conservación del Fondo de Justicia colonial de Córdoba. Dir. Constanza González Navarro. Córdoba: Centro de Estudios Históricos "Prof. Carlos S.A. Segreti”, 2017. 
Martínez de Sánchez, Ana María. Formas de la vida cotidiana en Córdoba (15731810). Espacio, tiempo y sociedad. Córdoba: Centro de Investigaciones y Estudios sobre Cultura y Sociedad, 2011.

“Indumentaria, 'ser' y 'parecer' en la Córdoba del setecientos”. Páginas sobre Hispanoamérica colonial. Sociedad y cultura. Volumen 1. Buenos Aires: Publicación del Programa de Investigaciones sobre Hispanoamérica Colonial / Consejo Nacional de Investigaciones Científicas y Técnicas, 1994.

Michaud, Yves. El nuevo lujo. Experiencias, arrogancia, autenticidad. Buenos Aires: Taurus, 2015.

Moreyra, Cecilia. "Entre lo íntimo y lo público: la vestimenta en la ciudad de Córdoba a fines del siglo XVIII". Fronteras de la Historia 15.2 (2010): 388-413.

. "La ropa, lo masculino y lo civilizado. La vestimenta de los hombres en Córdoba (Argentina), siglo XIX”. Temas Americanistas 33 (2014): 84-112.

Oudin, Fanny. “L'habit fait-il le moine? Quelques réflexions autour des proverbes vestimentaires du Moyen Âge". Questes. Revue Pluridisciplinaire d'Études Médiévales 25 (2013): 121-124. DOI: 10.4000/questes.137.

Pérez Toral, Marta. "El léxico de tejidos en inventarios notariales del siglo XVII". Revista de Lexicografía 23 (2017): 157-184. DOI: 10.17979/ rlex.2017.23.0.4701.

. "Tejidos y textiles en la vida cotidiana del siglo XVII". Revista de Investigación Lingüística 20 (2017): 195-219.

Piana de Cuestas, Josefina. Los indígenas de Córdoba bajo el régimen colonial (15701620). Córdoba: Dirección General de Publicaciones de la Universidad Nacional de Córdoba, 1992.

Presta, Ana María. "Undressing the Coya and Dressing the Indian Woman: Market Economy, Clothing, and Identities in the Colonial Andes, La Plata (Charcas), Late Sixteenth and Early Seventeenth Centuries". Hispanic American Historical Review 90.1 (2010): 41-74. DOI: 10.1215/001821682009-090.

Roche, Daniel. La culture des apparences. Une histoire du vêtement. XVIIe-XVIIIe siècle. París: Fayard, 1989.

Rodríguez de Tembleque, Carmen. "Un traje para la insinuación, la provocación y el recato”. Ponencia, Congreso Internacional Imagen Apariencia, Universidad de Murcia, 2008. https://dialnet.unirioja.es/servlet/ libro? codigo $=357306(03 / 09 / 2020)$.

Sarti, Raffaella. Vida en familia. Casa, comida y vestido en la Europa moderna. Barcelona: Crítica, 2003. 